them not only willing but eager to go, in order to effect a cure.

To assume that it is necessary to use Army discipline to compel a tuberculous soldier to enter a sanatorium is to deny all professional experience in dealing with that class of cases. It may be true that the old Regular Army man of experience may refuse to go to a sanatorium for reasons not necessary to state here; but I think Colonel Bruns has erred in assuming that the men of the selective army will entertain similar views. Thousands of the selective army come from excellent home environment, and there is a considerable proportion of patients who can be properly and successfully managed in their own homes under the care of their trusted family physicians. Many of them are from the rural districts where they can live in the open under the most favorable hygienic conditions.

In pursuing the course of treatment outlined by Colonel Bruns, the Army Medical Corps will not only deprive the soldier and his family of the compensation for disability which is payable to him only after his discharge, but I venture the opinion that this illegal detention of men unfit for further military service will result in an embarrassing number of legal procedures instituted by the families of these men to procure their freedom and their return to civil life where they belong. Return to civil life is the plan followed in England. I quote from an article by Major P. Horton-Smith Hartley, C.V.O., on "The Care of the Tuberculous Soldier" (British Medical Journal, 1918, 1, 609), in which he writes:

As soon as it is evident that the patient is suffering from phthisis, or even when this is strongly suspected, he is sent home to one of the military hospitals in this country. If there is no doubt about the diagnosis he comes before a medical board, and in due course is invalided from the army, his further treatment being undertaken by the civil authorities.

This is in line with the logical policy of the act creating the Bureau of War Risk Insurance which authorizes the compensation and, in certain cases, the payment of insurance for discharged men, and is the civil authority charged with providing men of no further military value with hospitalization whenever and wherever necessary. The existing sanatoriums for the treatment of tuberculosis throughout the country, with their experienced and already trained staffs, are not only able but also eager to open and extend their establishments for these discharged soldiers, as I know from official dealings with them. The proposed plan means the development of an enormous permanent military establishment, seeping into all the common activities of civil life, and whatever its theoretical value from the standpoint of the disciplinary treatment of tuberculosis, it is sure to invite widespread opposition from the soldier himself, whose right to a discharge cannot be successfully denied.

Charles E. Banks, M.D., Washington, D. C.

Chief Medical Adviser, Bureau of War Risk Insurance.

\section{SAVING THE WASTE IN DRUGS}

To the Editor:-In an attempt to reduce the drug bills at the Bryn Mawr Hospital, the following experiment has been tried:

A list of all the stock on hand was prepared by the night nurses, and it was found that there were, for the seventy beds, about 650 articles on the medicine shelves. This list, of course, included many duplicates or different preparations of the same drugs, as digitalis, and many different strengths of the same drug, for example, eight preparations of calomel in various denominations and in combination with various amounts of soda. There were also many special preparations that had been used a few times in the remote past and had been untouched since.

A list of drugs that seemed an irreducible minimum was then prepared, the editorial on "Sodium versus Potassium" (The Journal, June 1, 1918, p. 1601) being borne in mind, and submitted to the staff for its approval or correction. It comprised some sixty standard preparations, including, for example, calomel in halves and tenths only, morphin in quarters and twelfths, strychnin in thirtieths and fortieths, etc., from which other strengths conld readily be made.
It is intended that all future orders shall be made in accordance with this list, and that no special prescriptions shall be written under unusual circumstances. From experience in other hospitals, I have no doubt there is a vast amount of medicine "rusting" on the shelves throughout the country. Frederic C. Sharpless, M.D., Bryn Mawr, Pa.

\section{A SMALLPOX EPIDEMIC AMONG THE MIAO PEOPLE OF HAINAN}

To the Editor:-May 1, 1918, a man came out of the mountains in the interior of Hainan from a Miao village, stating that smallpox had broken out, and asking for vaccine. The Miao people are semiaboriginal, and live by themselves in the depths of the forest. An epidemic of any kind is liable to be extremely disastrous to them.

An assistant was sent in with vaccine. June 13 , the chief of the village came to the hospital and reported that smallpox had carried off nearly half of the village. Knowing that the vaccine sent in had been fresh, this information was surprising, and close inquiry brought out the following facts:

1. The epidemic had been extremely fatal.

2. All unvaccinated persons infected died. There were a number in the village not vaccinated, because a sufficient supply was not available, and it takes from two to three weeks for a supply to come from Hongkong.

3. About seven of those vaccinated contracted the disease and died, but in each of these cases the onset was less than four days after vaccination.

4. Several of those vaccinated contracted the disease, but only in a mild form. In these cases the onset was from six to seven days after vaccination.

5. The remainder of those vaccinated did not contract the disease.

6. Surrounding villages escaped the epidemic by voluntarily shunning all intercourse with the stricken village.

These facts are interesting because all the points reported were noted by the chief himself, and conform with remarkable accuracy to our knowledge of the epidemiology of the disease. Nathaniel Bercovitz, M.D., Kachek, Hainan, China.

\section{Queries and Minor Notes}

Anonymous Communications and queries on postal cards will not be noticed. Every letter must contain the writer's name and address, but these will be omitted, on request.

DIPLOSAL AND ACETYLSALICYLIC ACID

To the Editor:-For five or six years I have been using diplosal entirely instead of the soluble, irritating, nauseous salicylates. Since the war has been going on, diplosal has become so scarce that its cost is prohibitive to my poorer patients. I would regret having to return to sodium salicylate, so I am writing to ask if American pharmacy is supplying a practical substitute or equivalent of diplosal. If not, please advise me what $I$ can best prescribe.

SAM Uel E. WoOdy, M.D., Louisville, Ky.

Answer.-Possibly because it is not now advertised, the demand for diplosal is not sufficient to induce American manufacturers to apply to the Federal Trade Commission for a license to manufacture this product in the United States. Diplosal is the salicylic ester of salicylic acid, and in the intestine is broken up into salicylate. The only advantages of diplosal over sodium salicylate, as pointed out by our correspondent, consist in its lesser solubility, and therefore in the taste. The same advantages are possessed by acetylsalicylic acid, which may be used in the same dosage as diplosal.

\section{GRIMBERT'S METHOD-HAY SULPHUR TEST}

To the Editor:-1. Please describe Grimbert's method for determining bile pigments. 2. What is the Hay sulphur test for bile salts in the urine? Louis Hanna, M.D., Sandersville, Ga.

ANSwER.-1. Ten parts of urine are treated with 5 parts of barium chlorid solution, and the precipitate is filtered off and then suspended in 4 parts of alcohol containing 5 per cent. 